\title{
Seré Millones: el cine político y sus experiencias narrativas
}

Pablo Russo

Facultad de Humanidades y Ciencias, Universidad Nacional del Litoral

"Nuestras clases dominantes han procurado siempre que los trabajadores no tengan historia, no tengan doctrina, no tengan héroes y mártires. Cada lucha debe empezar de nuevo, separada de las luchas anteriores: la experiencia colectiva se pierde, las lecciones se olvidan. La historia parece así como propiedad privada cuyos dueños son los dueños de todas las otras cosas»

Rodolfo Walsh

Seré Millones trata sobre el desfalco más importante a un banco en la historia argentina contado por sus protagonistas, militantes del setentista Partido Revolucionario de los Trabajadores - Ejército Revolucionario del Pueblo, y actuado por las nuevas generaciones, en una mixtura de documental y ficción.
El cine social y político en nuestro país ha atravesado profundas transformaciones desde su resurgimiento durante la crisis del neoliberalismo y el estallido popular del cambio de siglo. Ha madurado y crecido en su lenguaje y en su experimentación, en parte porque también lo han hecho sus realizadores. Seré Millones (2013) es una muestra apasionada de ese desarrollo y también es, sin lugar a dudas, la película más interesante de los últimos tiempos sobre las formas posibles de revisar las luchas de nuestro pueblo. Este documental con momentos de ficción fue dirigido por Omar Neri, Fernando Krichmar y Mónica Simoncini, y producido en conjunto bajo la batuta de Alejandra Guzzo por Mascaró Cine Americano y 
Cine Insurgente, dos grupos audiovisuales con una vasta trayectoria en esta temática.

Oscar Serrano y Ángel Abus eran empleados del Banco Nacional de Desarrollo, además de militantes del Partido Revolucionario del Pueblo. Ellos fueron la pieza clave para el espectacular asalto de enero de 1972, conocido como «Operación Chauchas», en el que la organización política de izquierda expropió 450 millones de pesos de esa entidad bancaria (unos Io millones de dólares actuales) durante la dictadura del General Alejandro Lanusse. Nada fue para ellos, todo para la causa revolucionaria. Ambos protagonistas históricos participan en la reconstrucción del hecho (y vuelven al banco 40 años después), además de guiar a los jóvenes intérpretes que en un principio desconocen quiénes son esos hombres que los seleccionan en un casting. En el proceso de filmación vemos cómo este grupo de actores, participes involuntarios de una cámara oculta que luego formará parte de la edición final, va transformando su punto de vista respecto de la militancia y al compromiso político. Con escenografías teatrales simples al estilo Lars von Trier y actos que se repiten mezclando personajes verdaderos y representados, se repasan los hechos puntuales y el sentido épico de aquella sustracción. Resulta interesante notar que las formas en las que se manifiesta la memoria no siempre coinciden, como queda expuesto en la discusión entre Oscar y Ángel en la escena en la que recuerdan cómo fue la despedida con su comandante Roberto Santucho en La Habana, Cuba. El relato se apoya también en la sorpresa (la de los actores pero también la de otros personajes), y recupera el humor como forma de transmitir empatía y emociones (desde el título mismo), algo que tan oportunamente ensayaron Santiago Álvarez y Raymundo Gleyzer, referentes ineludibles del cine militante latinoamericano. La narración se complementa con una rigurosa investigación histórica que aporta materiales de archivo tales como fotografías, diarios, noticieros e incluso el rescate del comunicado fílmico del golpe al banco, realizado por el grupo Cine de la Base en 1972.

¿Hubiera sido posible imaginar una película como esta, sobre el trasfondo de uno de los capítulos más ocultos de la guerrilla, I5 años atrás? La historia del PRT-ERP, experiencia político-militar de las más importantes dentro del pensamiento y la militancia de izquierdas en la Argentina, estuvo callada durante años. Los motivos exceden estas líneas, pero posiblemente puedan rastrearse en la derrota que sufrió la organización, así como también en el manto de silencio que la recuperación democrática impuso a través de la construcción teórica de los «dos demonios», durante la primavera alfonsinista. Además, hay que señalar que sus principales dirigentes fueron asesinados durante el genocidio de la última dictadura cívico-militar (1976-1983), de lo que se 
deriva que nadie intentara apropiarse de esa herencia trunca y que, muchas veces, los viejos militantes esquivaran el recuerdo y la reivindicación pública. Esa tendencia comenzó a revertirse a mediados de los años noventa, con la aparición de la agrupación hijos (Hijos x la Identidad y la Justicia contra el Olvido y el Silencio), quienes intentaron reivindicar las luchas de los setenta desde otras perspectivas. En la bisagra del siglo, la crisis terminal del sistema neoliberal que llevó al estallido de diciembre de 200I acentuó esos intentos de recuperación de luchas históricas por parte de las jóvenes generaciones militantes. Como una necesidad ante un presente que se enfrentaba con ausencias de herramientas transformadoras, y como una reivindicación histórica en épocas de revisionismo, surgieron grupos de cine que tomaron la figura de Raymundo Gleyzer como bandera, e indagaron en su participación y compromiso político. Sus materiales, desde Los traidores hasta los Comunicados del PRT-ERP, comenzaron a circular con interés creciente para un público ávido y renovado. Los realizadores audiovisuales formados al calor de estas nuevas experiencias de lucha encararon entonces una reivindicación de la historia y memoria del partido. Dentro de estos discursos recientes, la serie Gaviotas Blindadas (que incluye las tres partes de Gaviotas Blindadas; Clase, sobre la política sindical; y Un arma cargada de futuro, sobre la política cultural) producida por el grupo Mascaró, Cine Americano, constituye el aporte más exhaustivo sobre el tema. En ese trabajo, durante la investigación, Omar Neri y Mónico Simoncini se encontraron con Oscar Serrano y Ángel Abus, los dos militantes que abrieron las puertas del BANADE para la "Operación Chauchas» que se representa en Seré Millones. Cuenta Neri:

Siempre pensábamos que las películas iban dirigidas a los jóvenes porque queríamos que las nuevas generaciones conozcan por qué se peleaba en los setenta. Y el desafío era meter a esas nuevas generaciones dentro de la pantalla. Por eso se inventó todo este dispositivo de los actores y el encuentro con los protagonistas, para ver si funcionaba, era un experimento, fueron un montón de cosas, que incluyeron hasta las cámaras ocultas (Tierra en Trance $\mathrm{N}^{\circ} \mathrm{I} 2$ ).

\section{Y agrega Simoncini:}

Nos interesaba que hubiese gente joven (en la película) que no fuera militante, poder mostrar un proceso de acercamiento con los que habían planificado y robado el Banco. De hecho, tratamos que eso se vaya notando: cómo al conocerlos, al ver que son personas comunes, normales, van variando su forma de pensar (ídem).

La novedad estética que aporta Seré $M i$ llones tiene que ver precisamente con que, en general, el período se abarca desde el 

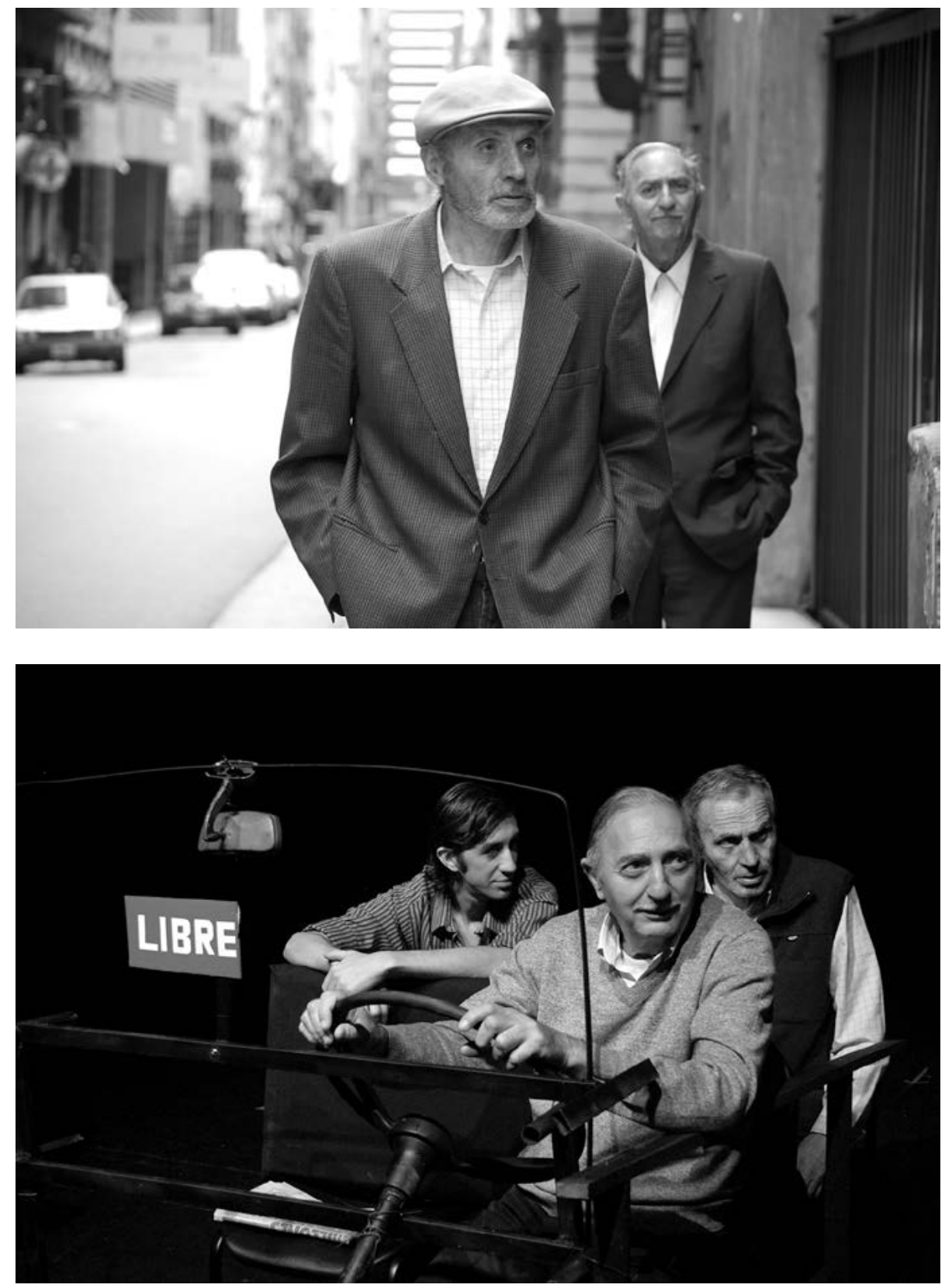
género documental, pero en el cruce con la ficción, los realizadores apuntan también a que su obra encuentre un público distinto. "Cada historia viene acompañada de su forma de contarse y también de las limitaciones que uno tiene, de las técnicas y de la imaginación que podamos poner en juego», señala Omar (ídem). Otros grupos de cine político contemporáneo están indagando en la ficción para sus narraciones: el Ojo Obrero (ligado al Partido Obrero) presentó ¿Quién mató a Mariano Ferreyra? (2013), y Contraimagen (brazo audiovisual del Partido de los Trabajadores Socialistas) estrenó en su canal de Internet la miniserie Marx ha vuelto, basada en el Manifiesto Comunista.

Muchas veces se dijo: la realidad supera la ficción, y esto es lo que se ve y disfruta en Seré Millones, el «documental» argentino con mayor asistencia de público de los últimos años (más de diez mil espectadores en salas oficiales en 20I4), premio especial del jurado en el Festival de Cine Político del 2013, que reconstruye nuestra historia y renueva las formas de narrarla. 
